\title{
Non-Hodgkin lymphoma of bone in an HIV-infected patient from Argentina
}

\author{
Uriel Sandkovsky ${ }^{1}$, Pablo F. Martin ${ }^{2}$ and Emiliano Bissio ${ }^{3}$ \\ ${ }^{1}$ Department of Internal Medicine and Division of Infectious Diseases, University of Nebraska Medical Center, \\ Omaha, NE, United States \\ ${ }^{2}$ Department of Internal Medicine, Hospital General de Agudos Dr Ignacio Pirovano, Buenos Aires, Argentina \\ ${ }^{3}$ Fundación Centro de Estudios Infectológicos (FUNCEI), Buenos Aires, Argentina
}

\begin{abstract}
Introduction: Human immunodeficiency virus (HIV)-infected patients are at higher risk for development of Non-Hodgkin's lymphoma (NHL). The estimated incidence of NHL in patients with acquired immunodeficiency syndrome (AIDS) is much higher when compared to the general population. Most AIDS-associated NHL are of intermediate- or high-grade B-cell type and involve extranodal sites more frequently. The most common sites are the central nervous system (CNS), gastrointestinal tract, liver, bone marrow and soft tissues.

Methodology: We describe a 42-year-old male with risk factors for HIV infection who presented with left leg pain and an osteolytic lesion of the left medial tibia. He was subsequently diagnosed with HIV disease and an open biopsy of his left tibia established the diagnosis of NHL. Results: After starting antiretroviral therapy followed by chemotherapy he achieved remission.

Conclusion: Bone lymphomas account for 3\% of malignant bone tumors and 4-7\% of all extranodal sites. NHL of bone has been infrequently described in patients with AIDS. To our knowledge, this is the first report of NHL of the bone in Argentina.
\end{abstract}

Key words: AIDS-related lymphoma; AIDS; HIV infection; non-Hodgkin lymphoma

J Infect Dev Ctries 2011; 5(11):815-819.

(Received 19 January 2011 - Accepted 11 April 2011)

Copyright $\odot 2011$ Sandkovsky et al. This is an open-access article distributed under the Creative Commons Attribution License, which permits unrestricted use, distribution, and reproduction in any medium, provided the original work is properly cited.

\section{Case report}

A 42-year-old Caucasian male was admitted to the Hospital General de Agudos Dr. Ignacio Pirovano, in November of 2000 with a two-month history of pain localized in the whole anterior tibial region of the left lower extremity, accompanied by 10 $\mathrm{kg}$ weight loss, intermittent fever with occasional night sweats, fatigue and anorexia. He lived with his wife and daughters and had been healthy until three months before admission when he was hospitalized elsewhere for pneumonia. He worked as a taxi driver; he was a smoker of 20 pack/years and used cocaine intermittently. He reported multiple unprotected sexual encounters with men and women.

On initial examination, he appeared in moderate distress due to pain in the left leg and required a cane to walk. He was febrile to $39^{\circ} \mathrm{C}$ and the rest of his vital signs were stable. He had oral candidiasis and small palpable lymph nodes in the neck. The cardiovascular, lung, abdominal, and neurologic examinations were unremarkable. He could not bear weight on his left leg and there was exquisite tenderness over the mid-third of his tibia but there was no swelling or increased temperature noted.
An X-ray of the left lower extremity demonstrated an osteolytic lesion of the tibia (Figure 1) and bone scintigraphy showed increased uptake of the tracer in the middle left tibia, knee and femoral head. An open bone biopsy was performed and revealed histology compatible with high-grade Burkitt-like, diffuse large B-cell lymphoma (Figure 2). Immunohistochemistry was positive for $\mathrm{CD} 10$ and negative for CD5, CD20, CD19, CD72 cell surface markers (null-type). Bone marrow biopsies of both iliac crests showed no bone marrow involvement. A computed tomography (CT) scan of the chest, abdomen and pelvis performed for staging purposes showed mediastinal lymphadenopathy of less than one centimeter, no hepatosplenomegaly and no enlarged abdominal, retroperitoneal, pelvic or inguinal lymph nodes. Enzyme-Linked Immunosorbent Assay and Western Blot analysis confirmed HIV-1 infection. The initial CD4 was 119 cells $/ \mathrm{mm}^{3}$, while viral load (VL) was 150,000 copies/mL.

Combination antiretroviral therapy (cART) was started with d4T, 3TC and saquinavir boosted with ritonavir, a standard antiretroviral regimen available 
Figure 1. X-ray of the right foot showing lytic destruction of the medial aspect of the tibia

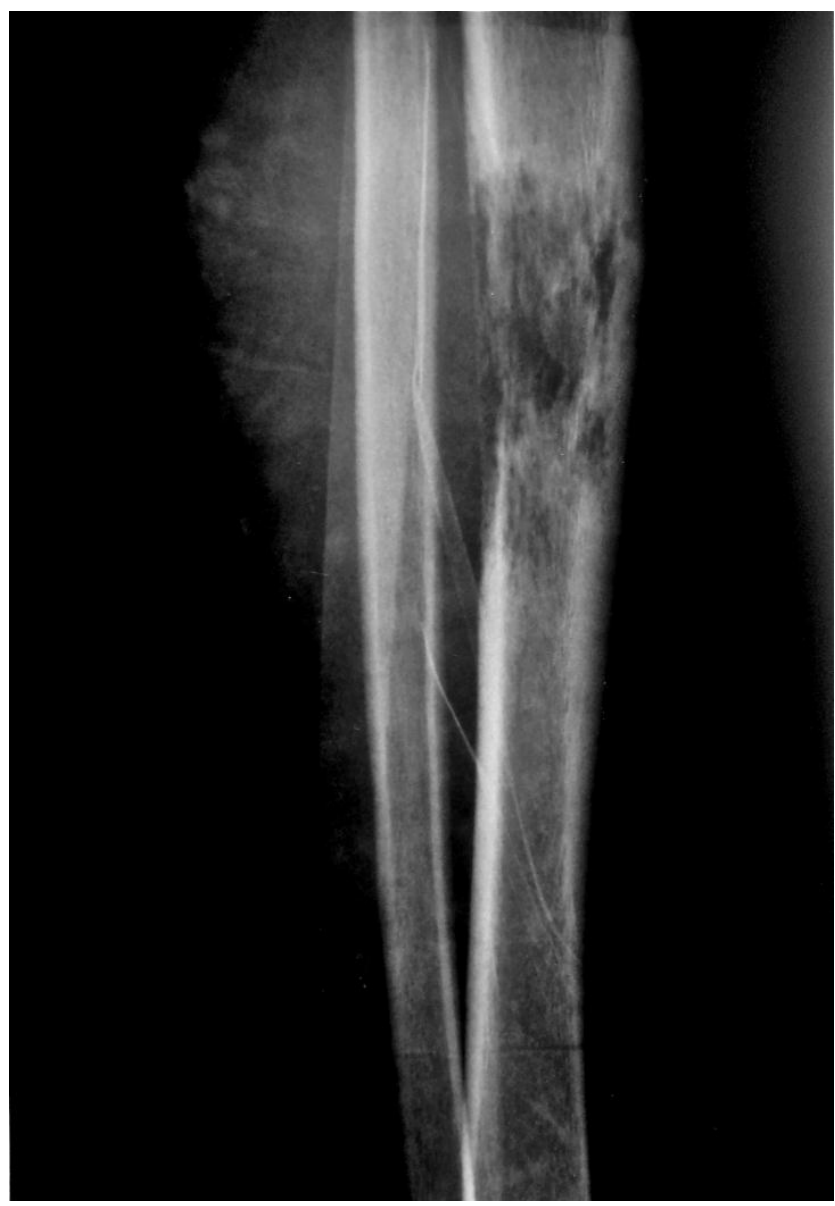

at the time. The patient underwent chemotherapy with cyclophosphamide, doxorubicin, vincristine and predsnisone (CHOP), which caused neutropenic fever and prolonged hospitalization.

After recovering from neutropenia, he was discharged on antiretroviral therapy and follow-up in the oncology and the infectious diseases clinics. He completed six cycles of CHOP chemotherapy without further complications. In the following months, the pain resolved and he was able to walk. The X-rays showed that a callus had formed where the osteolytic lesion had been in the tibia (Figure 3). Six months later, the CD4 count was 347 cells $/ \mathrm{mm}^{3}$, while VL was $<50$ copies/mL. Two years later, he stopped antiretroviral therapy because of severe distal sensory peripheral neuropathy; his antiretroviral regimen was changed several times but his viral load never became undetectable again. There was no evidence of recurrence of the lymphoma on serial clinical followups, and imaging showed stable X-rays with callus formation and no recurrence of lytic lesions. He succumbed three years later from cryptococcal meningitis at an outside hospital.

\section{Discussion}

The great majority of AIDS-NHL are high grade and of B-cell type [1]. AIDS-related lymphomas can be subdivided based on World Health Organization (WHO) criteria into 3 categories: 1) lymphomas that occur in immunocompetent patients such as Burkitt's lymphoma, diffuse large B-cell lymphoma, Extranodal Marginal zone B-cell lymphoma and peripheral T-cell lymphoma; 2) lymphomas that occur more frequently in patients with HIV disease, such as plasmablastic lymphoma and primary effusion lymphoma; 3) lymphomas that occur in other immunodeficiency states including posttransplant lymphoproliferative disorder-like B-Cell lymphoma. Most of AIDS-NHL share an aggressive course with extranodal disease and plasma cell differentiation [2].

The reasons patients with HIV infection have increased risk for development of NHL remains an area of further investigation. The causes underlying B-cell dyregulation remain unclear. Chronic immunosuppression, antigenic stimulation, immune activation, and dysregulated cytokine release, T-cell dysregulation, dendritic cell impairment, genetic abnormalities as well as the presence of Epstein-Barr (EBV) and human herpes virus-8 (HHV-8) virus infection may play a role in the pathogenesis of lymphoma in patients with HIV disease [2,3]. In the United States, both current CD4 cell count and prior time spent with a viral load above 500 copies $/ \mathrm{mL}$ were identified as risk factors for the development of lymphoma [4].

Figure 2. Hematoxylin and eosin stain showing histology compatible with high grade Burkitt-like, diffuse large B-cell lymphoma

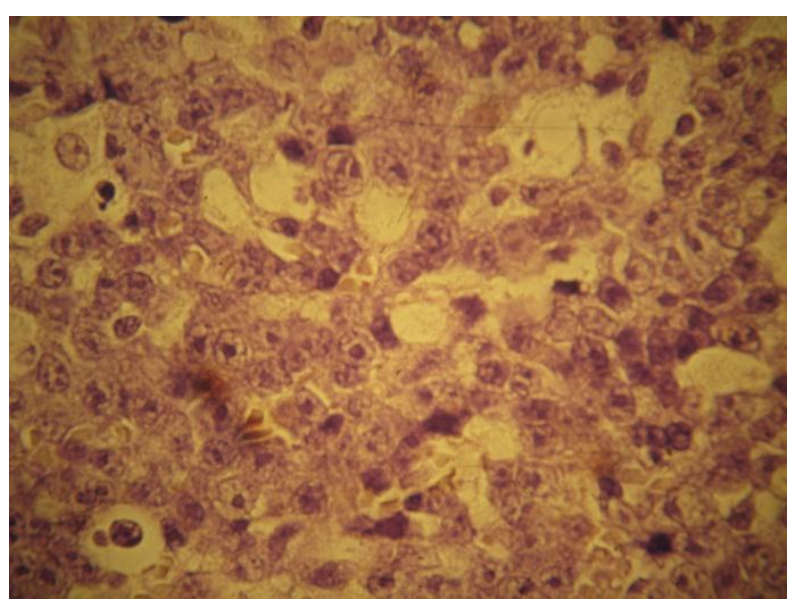


Figure 3. Follow-up X-ray of the right foot showing callus-bone formation on the medial tibia

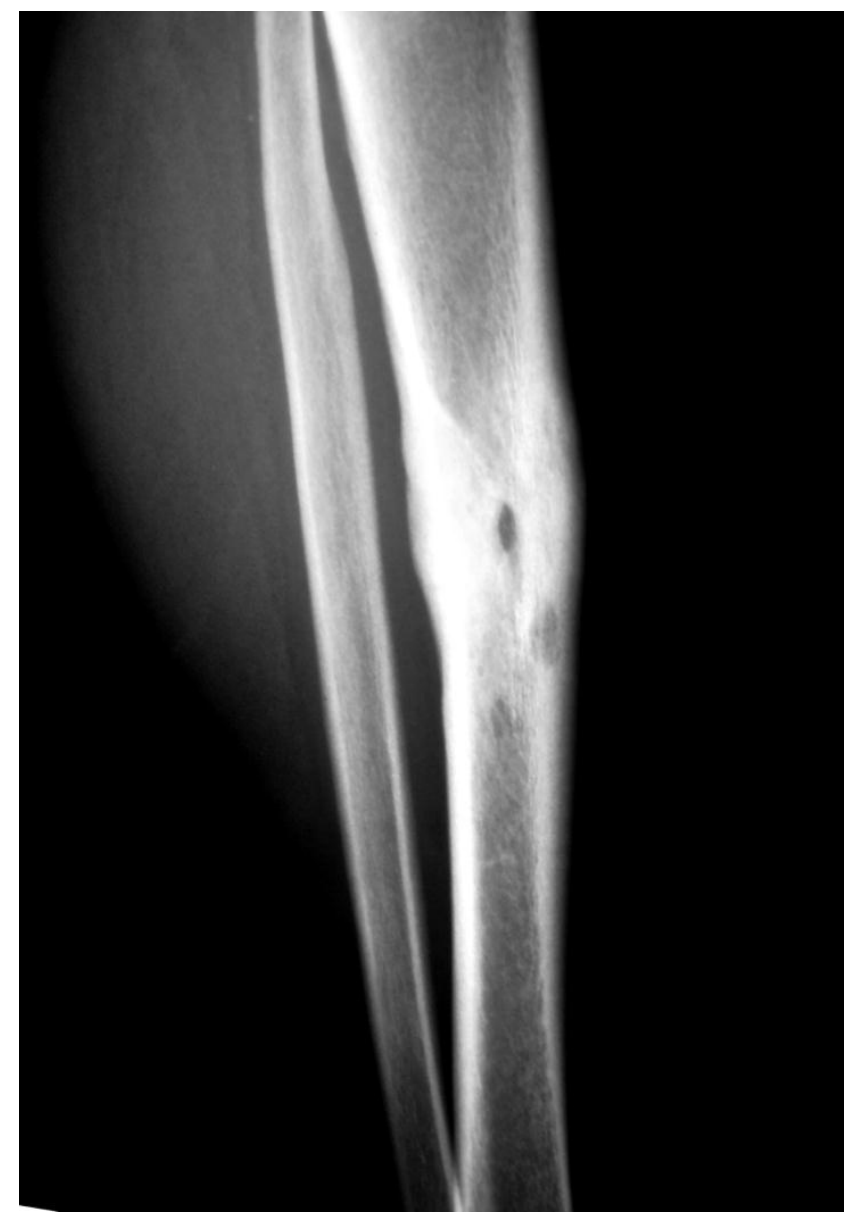

Patients harboring C-C chemokine receptor type 5 (CCR5) mutations, particularly heterozygous patients, have a three-fold lower risk of NHL compared to patients without this mutation [2].

AIDS-NHL is a life threatening complication of HIV infection. The median age of presentation is younger ( 37 years versus 65 years) and the incidence more than 100 times greater when compared to the general population. NHL is the AIDS-defining illness in about $3 \%$ of HIV-infected persons [2,5,6]. AIDSNHL are more frequently of high grade and more often involve extranodal sites. Patients tend to also have a more aggressive clinical presentation when compared to the general population, usually presenting with more advanced stage and the presence of B symptoms. Twenty to $30 \%$ of patients have concomitant bone marrow involvement $[2,3]$.

Although AIDS-NHL most often occurs with advanced HIV disease, it can also manifest at any CD4 count level. Burkitt and Burkitt-like NHL tend to occur at higher CD4 count levels [7]. This is in contrast to HIV-associated Hodgkin's lymphoma that tends to present a higher CD4 counts and is almost uniformly associated with EBV infection [7].

Staging of lymphoma is achieved with a combination of history, physical examination, clinical and laboratory data including cerebrospinal fluid examination, bone marrow biopsies and imaging studies such as CT scans of the chest, abdomen and pelvis or positron-emitted tomography (PET) scans [2].

Adverse prognostic criteria include ages greater than 35 years, history of intravenous drug abuse, CD4 counts less than 100 cells $/ \mu \mathrm{L}$, elevated serum LDH, advanced lymphoma stage, prior AIDS diagnosis and poor performance status [8]. In an analysis of 91 patients with AIDS-NHL (excluding primary CNS lymphoma) from the Swiss-HIV cohort study, Simcock et al. also identified CD4 counts less than 100 cells $/ \mu \mathrm{L}$, age greater than 40 years, elevated serum lactate dehydrogenase (LDH), extranodal disease, and an AIDS diagnosis as factors associated with poor prognosis. In that study, hepatitis $\mathrm{C}$ seropositivity was an independent predictor of mortality [9].

Primary NHL of bone is a rare entity accounting for only $3-7 \%$ of extranodal disease [10]. In the general population, primary lymphoma of bone represents only $5 \%$ of all extranodal NHL. The mean age at presentation is relatively young, 44 years (peaks at the fifth decade of life) or maybe younger, while it is more common in men than in women with a ratio of 1.8:1. The most frequent presenting symptom is localized bone pain and less frequently, a palpable mass. It affects mainly the long bones of the lower half of the body. The most common histology is diffuse large B-cell lymphoma. Since most of the studies about this type of lymphoma are retrospective case series or case reports, there are no clinical practice guidelines for its management. Most authors conclude that combined treatment with radiation and chemotherapy would be the best way the treat these patients [10].

The available literature for HIV-infected patients is even more scarce and limited to a few case reports. Aboulafia et al. reported a case of a 35-year-old man with AIDS-related NHL who was presented with lytic lesions in the tibia; in this patient the presentation was disseminated with diffuse lymphadenopathy, hepatosplenomegaly, bone marrow involvement and widespread infiltration of the skin. In contrast, our patient had primary bone 
disease with absence of nodal or bone marrow compromise and received treatment with antiretroviral therapy and systemic chemotherapy but no radiation therapy $[11,12]$.

Conventional X-rays usually show the presence of lytic lesions. The diagnosis is always made following biopsy and histopathological evaluation. Careful staging is important to differentiate primary lymphoma from bone lesions arising from another nodal or extranodal site [10].

When a patient with advanced HIV disease such as the one in this report presents with lytic bone lesions, the differential diagnosis is broad and may include the following: bacillary angiomatosis; Kaposis's sarcoma; multiple myeloma; bone metastasis; hematogenous osteomyelitis, especially in patients with a history of intravenous drug abuse; histoplasmosis; and mycobacterium tuberculosis, among others $[11,12]$.

Several cohorts have demonstrated a reduced incidence of AIDS-NHL since the advent of cART; however, HIV infection is still associated with an increased risk of lymphoma [3.

In two recently published cohorts severity and duration of immunosuppression were associated with the development of lymphoma but the latest CD4 cell counts had the strongest correlation [13,14].

There is evidence that patients with AIDS-NHL who have well-controlled infection will have better outcomes compared to patients with uncontrolled disease; therefore, it is acceptable to continue cART if the patient is already on it, but there is no consensus on what is the best approach for naive patients [15]. Some experts recommended the initiation of cART accompanied with chemotherapy in patients with AIDS-lymphoma, especially those with CD4 cells less than $100 / \mathrm{ml}$, despite the fact that no randomized trial has yet been completed to address this question. In this setting, the use of zidovudine should be avoided, as it may cause significant marrow suppression on its own [16].

Treatments for the most common subtype, diffuse large B-cell lymphoma, appear to be improving and phase II data have showed excellent outcomes with infusional therapy and concurrent rituximab [3]. The use of rituximab along with standard chemotherapy seems a feasible option. Caution should be used in patients with CD4 counts less than 50 cells $/ \mathrm{mm}^{3}$ due to higher risk of infectious complications and treatment-related deaths; however, supportive therapy and concurrent use of antibiotics has led to results similar to those seen in HIV- negative patients [16].

Autologous and allogeneic stem cell transplantation are also emerging therapeutic options in patients with refractory or relapsed NHL $[16,17]$. Research in this arena may become very interesting with different potential approaches, such as modification of immune targets. An example is the recent report of an HIV-infected patient with acute myelogenous leukemia who achieved complete remission and undetectable HIV viremia in the absence of antiretroviral therapy after receiving an allogeneic bone marrow transplant from a donor with homozygous deletion of the chemokine receptor CCR5 [18].

AIDS-NHL is an uncommon condition in the cART era. This case highlights the importance of a careful and thorough evaluation of patients with advanced HIV disease who present unusual signs and symptoms. Prompt diagnosis of this complication is a key factor, as new treatment approaches combining antiretroviral therapy and chemotherapeutic regimens have allowed improved survival.

\section{Acknowledgement}

We thank Dr Susan Swindells, MBBS, for her comments and editing of the manuscript.

\section{References}

1. Knowles DM (2003) Etiology and pathogenesis of AIDSrelated non-hodgkin's lymphoma. Hematol Oncol Clin North Am 17: 785-820.

2. Aboulafia DM, Pantanowitz L, Dezube BJ (2004) AIDSrelated non-Hodgkin lymphoma: Still a problem in the era of HAART. AIDS Read 14: 605-617.

3. Gucalp A and Noy A (2010) Spectrum of HIV lymphoma 2009. Curr Opin Hematol 17: 362-367.

4. Engels EA, Pfeiffer RM, Landgren O, Moore RD (2010) Immunologic and virologic predictors of AIDS-related nonHodgkin lymphoma in the highly active antiretroviral therapy era. J Acquir Immune Defic Syndr 54: 78-84.

5. Cote TR, Biggar RJ, Rosenberg PS, Devesa SS, Percy C, Yellin FJ, Lemp G, Hardy C, Geodert JJ, Blattner WA (1997) Non-Hodgkin's lymphoma among people with AIDS: Incidence, presentation and public health burden. AIDS/Cancer study group. Int J Cancer 73: 645-650.

6. Little RF, Gutierrez M, Jaffe ES, Pau A, Horne M, Wilson W (2001) HIV-associated non-Hodgkin lymphoma: Incidence, presentation, and prognosis. JAMA 285: 18801885.

7. Carbone A, Gloghini A, Serraino D, Spina M (2009) HIVassociated hodgkin lymphoma. Curr Opin HIV AIDS 4: 310.

8. Straus DJ, Huang J, Testa MA, Levine AM, Kaplan LD (1998) Prognostic factors in the treatment of human immunodeficiency virus-associated non-Hodgkin's lymphoma: Analysis of AIDS clinical trials group protocol 142--low-dose versus standard-dose m-BACOD plus granulocyte-macrophage colony-stimulating factor. National 
Institute of Allergy and Infectious Diseases. J Clin Oncol 16: 3601-3606.

9. Simcock M, Blasko M, Karrer U, Bertisch B, Pless M, Blumer L, Vora S, Robinson JO, Bernasconi E, Terziroli B, Moirandat-Rytz S, Furrer H, Hirschel B, Vernazza P, Sendi P, Rickenbach M, Bucher HC, Battegay M, Koller MT (2007) Treatment and prognosis of AIDS-related lymphoma in the era of highly active antiretroviral therapy: Findings from the Swiss HIV cohort study. Antivir Ther 12: 931-939.

10. Misgeld E, Wehmeier A, Kromeke O, Gattermann N (2003) Primary non-Hodgkin's lymphoma of bone: Three cases and a short review of the literature. Ann Hematol 82: 440-443.

11. Aboulafia AJ, Khan F, Pankowsky D, Aboulafia DM (1998) AIDS-associated secondary lymphoma of bone: A case report with review of the literature. Am J Orthop (Belle Mead NJ) 27: 128-134.

12. Song YG, Hahn JS, Choi YH, Yeom JS, Yang WI, Seo CO, Kim JM (1998) A case of primary bone lymphoma associated with acquired immunodeficiency syndrome. Yonsei Med J 39: 383-389.

13. Bower M, Fisher M, Hill T, Reeves I, Walsh J, Orkin C, Phillips AN, Bansi L, Gilson R, Easterbrook P, Johnson M, Gazzard B, Leen C, Pillay D, Schwenk A, Anderson J, Porter K, Gompels M, Sabin CA (2009) CD4 counts and the risk of systemic non-Hodgkin's lymphoma in individuals with HIV in the UK. Haematologica 94: 875-880.

14. Collaboration of Observational HIV Epidemiological Research Europe (COHERE) Study Group, Bohlius J, Schmidlin K, Costagliola D, Fätkenheuer G, May M, CaroMurillo AM, Mocroft A, Bonnet F, Clifford G, Karafoulidou
A, Miro JM, Lundgren J, Chene G, Egger M (2009) Incidence and risk factors of HIV-related non-Hodgkin's lymphoma in the era of combination antiretroviral therapy: A European multicohort study. Antivir Ther 14: 1065-1074.

15. Little RF, Pittaluga S, Yarchoan R (2008) Non-Hodgkin Lymphoma in Dolin R, Masur H, Saag MS. AIDS Therapy. 3rd ed. Philadelphia, PA: Churchill Livingstone/Elsevier. 1031-1050.

16. Levine AM (2008) Management of AIDS-related lymphoma. Curr Opin Oncol 20: 522-528.

17. Krishnan A and Forman SJ (2010) Hematopoietic stem cell transplantation for AIDS-related malignancies. Curr Opin Oncol 22: 456-460.

18. Hutter G, Nowak D, Mossner M, Ganepola S, Müssig A, Allers K, Schneider T, Hofmann J, Kücherer C, Blau O, Blau IW, Hofmann WK, Thiel E (2009) Long-term control of HIV by CCR5 Delta32/Delta32 stem-cell transplantation. N Engl J Med 360: 692-698.

\section{Corresponding author}

Uriel Sandkovsky, MD

Division of Infectious Diseases

University of Nebraska Medical Center

988106 Nebraska Medical Center

Omaha, NE. 68198-8106

Telephone: 1 (402) 559-8664; Fax: 1 (402) 553-5527

Email: usandkovsky@unmc.edu

Conflict of interests: No conflict of interests is declared. 